\title{
Analysis on Evaluation of Ecological Security Based on Remote Sensing Data
}

\author{
SUN Caige \\ Guangzhou Institute of Geography \\ Guangzhou,China \\ gecaisun@163.com
}

\author{
ZHONG Kaiwen* \\ Guangzhou Institute of Geography \\ Guangzhou,China \\ zkw@gdas.ac.cn
}

\begin{abstract}
The eco-security of Dongjiang watershed was evaluated in 1988, 1998 and 2007 separately after the eco-security index system establishment, which included three first-class indicators and eighteen second-class indicators based on P-S-R model. The eco-security dynamic degree was built to analysis the temporal and spatial variation of the countries and cities. Some guiding ideas and practicing tactics has been put forward to promote the watershed eco-security.
\end{abstract}

Index Terms-Eco-security; Eco-security dynamic degree; Remote Sensing Data

\section{INTRODUCTION}

Watershed is a complex ecosystem, composed by socioeconomic system, natural systems and water system components. It has abundant land and water resources, raising the human and supporting the social and economic development. However, with the population explosion and the rapid economic development, natural ecosystems have been destroyed. Environmental pollution and resource shortage increase seriously, accompanying ecological damage, such as soil erosion, destruction of vegetation, loss of biodiversity, etc.
These factors have seriously affected the ecological security of the system. How to quantitatively evaluate the state of the ecological security is a difficult problem in the subject of regional eco-environmental management and decision-making. So the research of eco-security in watershed is of great scientific significance and practical significance.

\section{STUDY AREA AND RESEARCH DATA}

The area of this study is Dongjiang watershed, which located from $113^{\circ} 29^{\prime} \mathrm{E}$ to $115^{\circ} 41^{\prime} \mathrm{E}, 22^{\circ} 23^{\prime} \mathrm{N}$ to $24^{\circ} 47^{\prime}$ $\mathrm{N}$. The area of Dongjiang watershed is $35340 \mathrm{~km}^{2}$, among it, $90 \%$ in Guangdong province. It has the typical subtropical monsoon humid climate, average annual temperature $20^{\circ} \mathrm{C}$ $22^{\circ} \mathrm{C}$, and the precipitation is $1500 \mathrm{~mm}-2400 \mathrm{~mm}$. With the rapid economic development in the recent 20 years, ecosystems have been destroyed.

TM images of 1988, 1998 and 2007 were acquired for the study respectively. Moreover, the data of DEM, water quality assessment, statistical yearbook and meteorological record etc. were also been collected.

TABLE I. TABLE TYPE STYLES WEIGHT DISTRIBUTION OF INDEXES FOR ECOLOGICAL SECURITY EVALUATION

\begin{tabular}{|c|c|c|c|}
\hline $\begin{array}{l}\text { Criterion layer } \\
\text { (Weight) }\end{array}$ & $\begin{array}{l}\text { Element layer } \\
\text { (Weight) }\end{array}$ & Indicator layer(Weight) & $\begin{array}{c}\text { Normalized } \\
\text { weight }\end{array}$ \\
\hline \multirow{8}{*}{$\begin{array}{c}\text { Eco-security Pressure } \\
(0.35)\end{array}$} & \multirow{2}{*}{$\begin{array}{c}\text { Resource pressure } \\
(0.2)\end{array}$} & Farmland areas per person $(0.33)$ & 0.023 \\
\hline & & land degradation index $(0.67)$ & 0.047 \\
\hline & \multirow{3}{*}{$\begin{array}{l}\text { Social pressure } \\
\qquad(0.3)\end{array}$} & population density $(0.20)$ & 0.021 \\
\hline & & Pressure from residential points $(0.40)$ & 0.042 \\
\hline & & Pressure from traffic line $(0.40)$ & 0.042 \\
\hline & \multirow{3}{*}{$\begin{array}{c}\text { Environmental pressure } \\
(0.5)\end{array}$} & Intensity of fertilizer application per farmland area $(0.33)$ & 0.058 \\
\hline & & Influence degree of sand mining $(0.53)$ & 0.093 \\
\hline & & River water quality $(0.14)$ & 0.024 \\
\hline \multirow{8}{*}{$\begin{array}{c}\text { Eco-security State } \\
(0.55)\end{array}$} & \multirow{4}{*}{$\begin{array}{l}\text { natural conditions } \\
\qquad(0.5)\end{array}$} & Elevation index (0.30) & 0.083 \\
\hline & & slope index $(0.40)$ & 0.110 \\
\hline & & Annual average temperature $(0.10)$ & 0.028 \\
\hline & & Annual rainfall $(0.20)$ & 0.055 \\
\hline & \multirow{4}{*}{$\begin{array}{l}\text { resources quantity } \\
\qquad(0.5)\end{array}$} & vegetative cover index $(0.38)$ & 0.104 \\
\hline & & Rivers density index $(0.14)$ & 0.038 \\
\hline & & organism abundance index $(0.28)$ & 0.077 \\
\hline & & soil index $(0.20)$ & 0.055 \\
\hline \multirow{2}{*}{$\begin{array}{c}\text { Eco-security Response } \\
(0.1)\end{array}$} & \multirow{2}{*}{$\begin{array}{l}\text { social response } \\
\text { (1) }\end{array}$} & per capita GDP (0.67) & 0.067 \\
\hline & & environmental protection $(0.33)$ & 0.033 \\
\hline
\end{tabular}




\section{RESEARCH METHOD}

The index system was established including three firstclass indicators and eighteen second-class indicators. The weight of each hierarchy is valued and calculated by the analytical hierarchy process considering the expert's weighted vectors(such as TABLE I ).

A pixel was taken as the basic evaluation unit. Thematic maps were spatial overlay after standardized processing, using the weight sum method. The index of eco-security in each pixel and the comprehensive index in each country have been calculated by the models, in order to achieve a quantitative evaluation of the regional eco-security.

The models of eco-security index:

$$
\begin{aligned}
A_{i} & =\sum_{k=1}^{n} W_{k} Y_{k} \\
C_{i} & =\frac{\sum A_{i} \times S_{i}}{\sum S_{i}}
\end{aligned}
$$

(Formula 1)

$\mathrm{A}_{\mathrm{i}}$ denotes the eco-security in the ith pixel; $\mathrm{W}_{\mathrm{k}}$ denotes the weight of the $k$ th index in the same pixel; $Y_{k}$ denotes the quantitative value after standardized processing. $C_{i}$ denotes the comprehensive eco-security of the ith country; $\mathrm{S}_{\mathrm{i}}$ denotes the number of $A_{i}$ in the same country. The result is a value between $0 \sim 10$, and the larger the better.

For the purpose of comparison, and according to practical situation, the eco-security was divided into six levels. From level I to level VI, the eco-security is worse and worse.

Borrowed the model of land-use change, the eco-security dynamic degree model has been built. It is the quantity change within a certain period and a certain area, which reflects the changing trend and degree of the eco-security more intuitive and accurate.

$$
S=\frac{U_{b}-U_{a}}{U_{a}} \times \frac{1}{T} \times 100 \%
$$

(Formula 3)

$\mathrm{S}$ denotes the eco-security dynamic degree in the studied time period. $\mathrm{U}_{\mathrm{a}}$ and $\mathrm{U}_{\mathrm{b}}$ denote respectively the eco-security dynamic degree at the beginning of the study period and at the end of the study period. If taken year as the unit, $S$ denotes the annual changing rate of the eco-security dynamic degree. When $S$ is calculated into a positive number, the eco-security is improved, vice versa, worsen. $|S|$ denotes the range of the improved eco-security or the worsen eco-security.

\section{RESULT AND DISUSSIONS}

In 1988, the mean value of the eco-security in Dongjiang watershed is 6.55, Fig. 1 and Fig. 2 reveal there were three, six and five cities in level I, level II and level III separately. Shenzhen internal had the lowest the eco-security. There was no city in level V or level VI.

In 1998, The eco-security range of each city was from 5.18 to 7.14 . Compare with 1988 , the cities lie in level I had no changes, while the cities number of level II increase to eight; and level III reduce to three. It is worth to say that the ecosecurity of Dongguan had been improved a little, which located level IV in 1988 and level III in 1998; while Huicheng was exactly the opposite. Tough the eco-security of 1998 is better than that of 1988 on the surface, the actual eco-security was only 6.48 in 1998 , which was reduced by $1.1 \%$; because the eco-security of Shenzhen internal and external all had fell into level $\mathrm{V}$ from level IV.There was no city in level VI.

In 2007 , the eco-security of was not optimistic, with the mean eco-security value only 6.18 , which reduced by $4.83 \%$ compare with 1998. The city in level VI appeared, Shenzhen
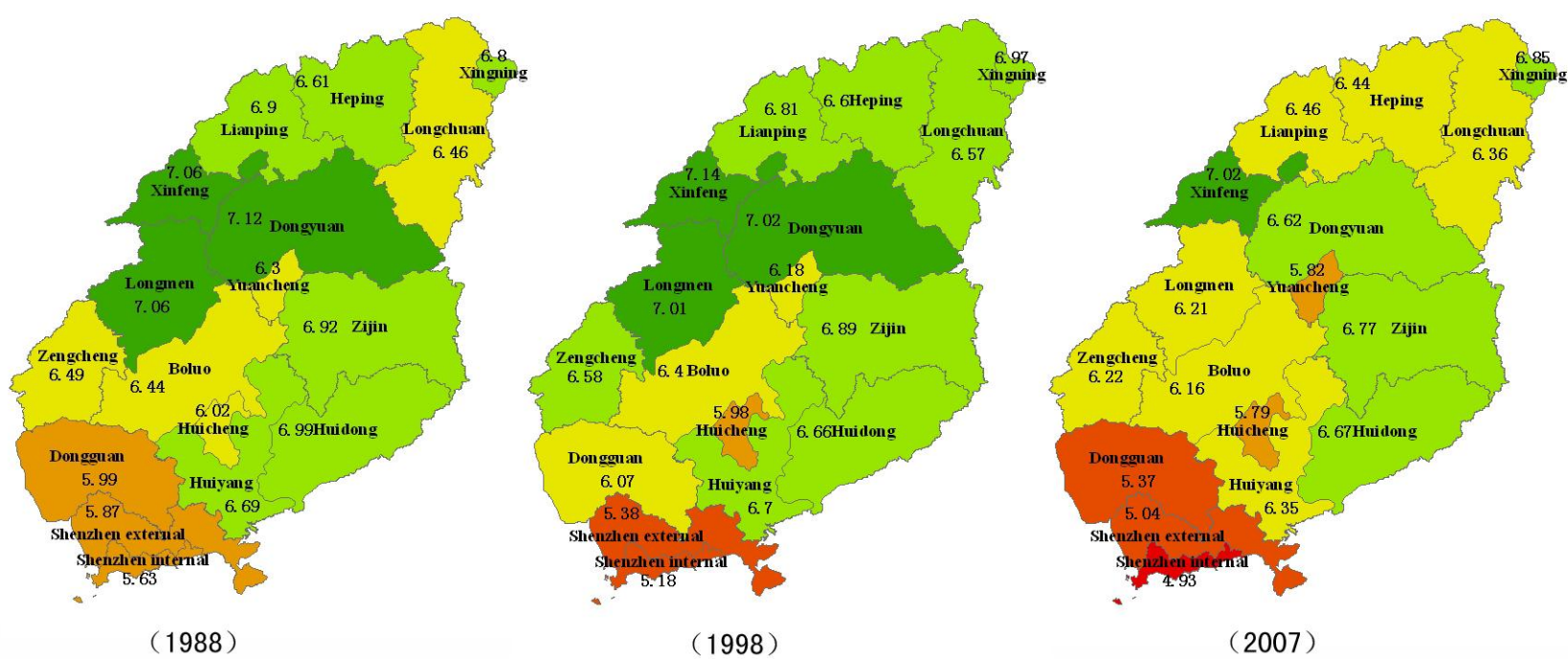

(2007)

Leve1 I Leve1 II Leve1 III Level IV Level V Leve1 VI

Fig.1 Eco-security evaluation result in different cities 
internal, with the eco-security just 4.93. Among all the city eco-security values, the best was 7.02, which was lower than that in 1998. The total number of cities in level I , level II and level III was reduced to twelve. There was only Xinfeng keeping very safety state. Yuancheng was fell into level IV from level III and Dongguan was fell into level $\mathrm{V}$ from level III.

The eco-security changes in every county and town can be seem clearly from Fig. 3 and TABLE II. In the early 10 years, the changes were not obvious, except Shenzhen, whose ecosecurity was getting worse and worse. But a phenomenon that the eco-security was a slightly better also appeared in some county and town. In the last 9 years, the whole eco-security was seriously deteriorated, with every county and town had different degrees of decline in the quality of the eco-security.

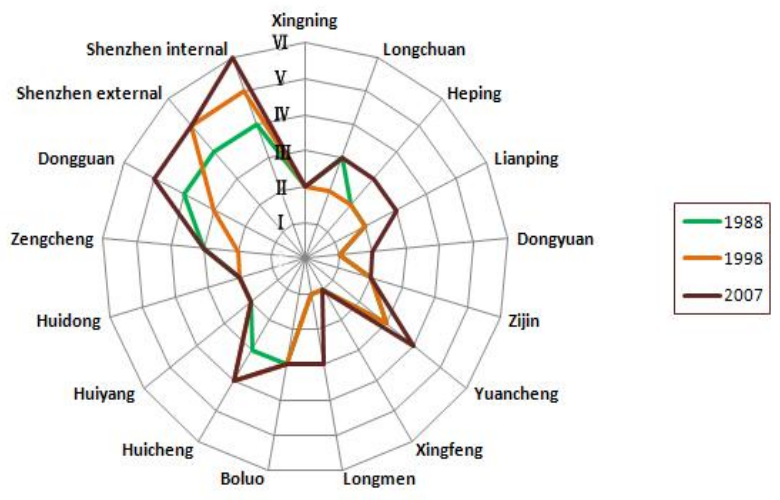

Fig.2 Eco-security evaluation level in different cities

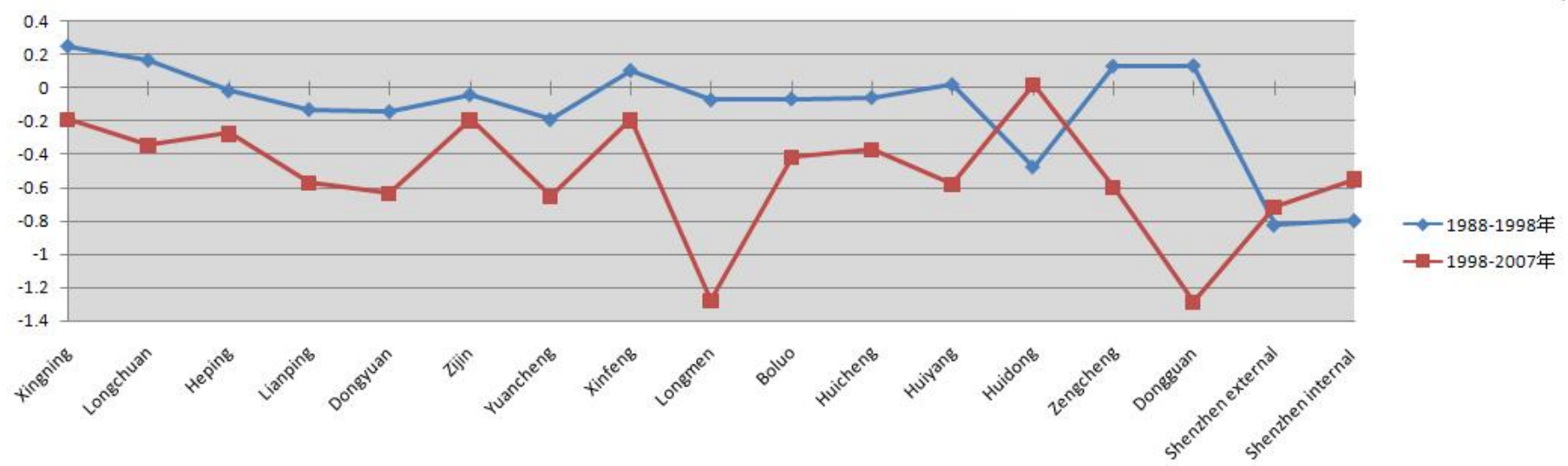

Fig.3 Eco-security dynamic degree in different cities in different periods

TABLE II. TABLE OF ECO-SECURITY DYNAMIC DEGREE

\begin{tabular}{|c|c|c|c|c|}
\hline & Xinning & Longchuan & Heping & Lianping \\
\hline 1988-1998 & $0.25 \%$ & $0.17 \%$ & $-0.02 \%$ & $-0.13 \%$ \\
\hline \multirow[t]{2}{*}{$1998-2007$} & $-0.19 \%$ & $-0.35 \%$ & $-0.27 \%$ & $-0.57 \%$ \\
\hline & Dongyuan & Zijin & Yuancheng & Xinfeng \\
\hline $1988-1998$ & $-0.14 \%$ & $-0.04 \%$ & $-0.19 \%$ & $0.11 \%$ \\
\hline \multirow[t]{2}{*}{$1998-2007$} & $-0.63 \%$ & $-0.19 \%$ & $-0.65 \%$ & $-0.19 \%$ \\
\hline & Longmen & Boluo & Huicheng & Huiyang \\
\hline $1988-1998$ & $-0.07 \%$ & $-0.06 \%$ & $-0.06 \%$ & $0.02 \%$ \\
\hline \multirow[t]{2}{*}{$1998-2007$} & $-1.28 \%$ & $-0.42 \%$ & $-0.37 \%$ & $-0.58 \%$ \\
\hline & Huidong & Zengcheng & Dongguan & \\
\hline 1988-1998 & $-0.47 \%$ & $0.13 \%$ & $0.13 \%$ & \\
\hline \multirow[t]{2}{*}{$1998-2007$} & $0.02 \%$ & $-0.60 \%$ & $-1.28 \%$ & \\
\hline & \multicolumn{2}{|c|}{ Shenzhen external } & \multicolumn{2}{|c|}{ Shenzhen internal } \\
\hline 1988-1998 & \multicolumn{2}{|c|}{$-0.82 \%$} & \multicolumn{2}{|c|}{$-0.79 \%$} \\
\hline $1998-2007$ & \multicolumn{2}{|c|}{$-0.71 \%$} & \multicolumn{2}{|c|}{$-0.55 \%$} \\
\hline
\end{tabular}

From 1988 to 1998 , the eco-security of 6 cities had been improved. They are Xingning 、 Longchuan 、 Xinfeng 、 Huiyang 、 Zengcheng and Dongguan. The largest improvement range is $0.25 \%$, belonging to Xingning, which lies in upstream. In addition to these 6 cities, others had different degrees of decline in the quality of the eco-security, and the largest deterioration range was $0.82 \%$, belonging to Shenzhen external, next come Shenzhen internal and Huidong, with the deterioration range $0.8 \%$ and $0.47 \%$.

From 1998 to 2007, except Huidong, there was no improved city. The deterioration range of Lianping 、 Dongyuan 、Yuancheng 、 Huiyang 、 Zengcheng 、 Longmen、Dongguan and Shenzhen external were more than $0.55 \%$, worse still, Longmen and Dongguan reached to $1.28 \%$.

\section{SUMMARY}

Based on the Dongjiang current situation of the ecosecurity, the paper addresses some guiding ideas and practicing tactics in order to promote the watershed ecological steady development as follows: pollutant sources controlling and water quality protection; illegal sand mining regulation and mining environment conservation; pure eucalyptus forest transformation and species diversity enriching; water compensation mechanism perfecting and the economic development coordinating in different cities; "Digital Basin" 
building and ecological management informationization; watershed ecological monitoring, assessment and early warning systems establishing and information-sharing mechanisms creating.

\section{ACKNOWLEDGMENT}

This work was supported by Guangdong NSF (10151007003000002) and Comprehensive strategic cooperation project of the Chinese academy of sciences and Guangdong province (2011B090300048)

\section{REFERENCES}

[1] Wang Xiulan ,Bao Yuhai, "Study on the methods of land use dynamic change research," vol.18,no.1,1999, progress in geography, pp81-87

[2] HJ/T192 - 2006, Technical Criterion for Eco-environmental Status Evaluation (Trial Implementation), 2006

[3] Cheng Jinnan ,Zhao Gengxing ,Li Hong ,Tang Xiumei ,Suo Qiukui , "Dynamic changes and evaluation of land ecological environment status based on RS and GIS technique," vol.24,no.11,2008, Transactions of the Chinese Society of Agricultural Engineering, pp83-88
[4] Gao Qing-zhu,Xu Hong-mei,Kang Mu-yi,Yang Jie, Sun Lin, Zhao Yun-long, "Comprehensive Evaluation on Ecological Security in the Soft Rock Area in Middle Reaches of the Yellow River:A Case Study in Changchuan Watershed,China," vol,28,no.2,2006, Resources Science, pp132-139

[5] LI Hua, CAI Yong-li, "A Study of Ecological Security Evaluation of Chongming Island Based on the Frame of ANPPRS-SENCE", vol.25,no.3,2009, Geography and GeoInformation Science, pp90-94

[6] Li Xuan-qiong, He Zheng-wei, Chen Xiao-jie, Zhang Lin, Deng Cong, "Ecological security assessment of county area based on RS and GIS," vol.38,no.1,2013, Science of Surveying and Mapping, pp68-71

[7] Zhong Kai-wen, Sun Cai-ge, Liu XU-Long, Peng Long-jun, "Research on Ecological Security Evaluation of River Basin Based on RS and GIS," vol.39,2011, Journal of Anhui Agricultural Sciences, pp2192-2195

[8] Yang Yong, Ren Zhi-yuan, "Assessment and Analysis on the Ecological Security in the Middle and Lower Reaches of the Jinghe River Basin,"vol.26,no.3,2009, Arid Zone Research , pp441-446 